\title{
Review: compression treatment improves healing of venous leg ulcers
}

Fletcher A, Cullum N, Sheldon TA. A systematic review of compression treatment for venous leg ulcers. BMJ 1997 Sep 6;315:576-80.

\section{Objective}

To determine the effectiveness of compression treatment for venous leg ulcers using systematic review.

\section{Data sources}

Studies were identified using 19 bibliographic, citation, and research databases; searches of bibliographies of relevant papers; hand searches; and contact with manufacturers and authors.

\section{Study selection}

Studies were selected if they were randomised controlled trials (RCTs) which examined the effects of compression on the healing of venous leg ulcers.

\section{Data extraction}

Data were extracted (and checked by a second reviewer) on study inclusion and exclusion criteria, sample size, a priori sample size calculation, method of randomisation, comparability of treatment groups at baseline, blinded assessment of outcomes, use of appropriate outcome measures, and intention to treat analysis.

\section{Main results}

24 RCTs (6 unpublished) were included in the review. 6 treatment variables were analysed. Data for 3 variables (high $v$ low compression, multilayer $v$ single layer bandage, and adjunct intermittent pneumatic compression $v$ no intermittent pneumatic compression) were homogeneous, and meta-analyses were done. Elastic high compression multilayer bandages had increased healing at 3 months compared with inelastic multilayer compression bandages $\{\mathrm{p}<0.005\}^{*}$ (table 1). 4 layer bandages had increased healing at 12 weeks (2 trials) and 24 weeks ( 1 trial) compared with single layer bandages (Setopress, Granuflex, Porelast) $\{\mathrm{p}<0.005\} *$ (table 2$)$. The addition of intermittent pneumatic compression to compression stockings or Unna's boot was associated with increased healing $\{\mathrm{p}<0.005\} *($ table 3$)$.

2 of 3 trials which compared compression (using Unna's boot) with no compression (dressings only) found more healed ulcers with compression. 3 studies which compared different types of compression with no compression found improved healing with compression. No differences were reported in 3 studies which compared elastic high compression 4 layer bandages with inelastic compression bandages (Unna's boot, short stretch bandage).

\section{Conclusions}

Compression treatment improves healing of venous leg ulcers compared with no compression treatment, and high compression is more effective than low compression. Intermittent pneumatic compression as an adjunct to compression improves healing.

*p value calculated from data in article.

Table 1 Complete ulcer healing with elastic multilayer high compression $v$ inelastic multilayer compression $(n=3$ studies) $\dagger$

\begin{tabular}{lllll}
\hline $\begin{array}{l}\text { Elastic } \\
\text { weighted EER }\end{array}$ & $\begin{array}{l}\text { Inelastic } \\
\text { weighted CER }\end{array}$ & RBI (95\% CI) & $\begin{array}{l}\text { Weighted ABI } \\
\mid \text { EER-CER } \mid\end{array}$ & NNT (CI) \\
\hline $57.7 \%$ & $37.4 \%$ & $54 \%(19$ to 99$)$ & $20.3 \%$ & 5 (4 to 12)
\end{tabular}

Table 2 Complete ulcer healing with multilayer elastic high compression $v$ single layer $(n=3$ studies $) \dagger$

\begin{tabular}{lllll}
\hline $\begin{array}{l}\text { Multilayer } \\
\text { weighted EER }\end{array}$ & $\begin{array}{l}\text { Single layer } \\
\text { weighted CER }\end{array}$ & RBI $(95 \%$ CI $)$ & $\begin{array}{l}\text { Weighted } A B I \\
|E E R-C E R|\end{array}$ & NNT(CI) \\
\hline $65.3 \%$ & $46.1 \%$ & $41 \%(12$ to 77$)$ & $19.2 \%$ & $6(4$ to 14$)$ \\
\hline
\end{tabular}

Table 3 Complete ulcer healing with intermittent pneumatic compression $v$ no pneumatic compression ( $n=2$ studies) $\dagger$

\begin{tabular}{lllll}
\hline $\begin{array}{l}\text { Pneumatic } \\
\text { compression } \\
\text { weighted EER }\end{array}$ & $\begin{array}{l}\text { No preumatic } \\
\text { compression } \\
\text { weighted CER }\end{array}$ & $R B I(95 \%$ CI) & $\begin{array}{l}\text { Weighted ABI } \\
\mid \text { EER-CER } \mid\end{array}$ & NNT (CI) \\
\hline $52.7 \%$ & $26.5 \%$ & $123 \%(38$ to 261$)$ & $26.2 \%$ & $3(2$ to 7$)$ \\
\hline
\end{tabular}

†Abbreviations defined in glossary; RBI, ABI, and CI calculated from data in the article.

Source of funding: NHS Health Technology Assessment Programme.

For article reprint:Dr N Cullum, Department of Health Studies, The University of York, Heslington, York YO1 5DG, UK. Fax +44 (0)1904 435225.

\section{Commentary}

The management of venous leg ulcers has long posed a problem for nursing. Although the factors which influence the healing rate of venous leg ulcers are many, compression has been a consistent adjunct to the myriad of proposed treatments. A systematic review of RCTs examining the use of compression promises to be of great value to practice. This review by Fletcher $e t$ al is a useful one that has an explicit message for current nursing management of leg ulcers.

The purpose of the review and its methodology are described succinctly. The authors reviewed 24 RCTs and provided information on various aspects of the quality of each trial. This enables the reader to evaluate the strength of the evidence from each study. The strength of systematic reviews and meta-analyses lies in the fact that reviewers must predefine specific criteria for selecting studies for inclusion and for evaluating the quality of the studies.

There are great variations in compression treatment practices, particularly when international comparisons are made. For example, Unna's boot is used in North America, short stretch material in Europe and Australia, and elastic compression in the UK. Research evidence, as it stands, is poor, but what is clear is the importance of compression treatment, per se, and the need for nurses to be properly trained to use it. Recently, a great deal of debate has occurred about which type of compression is most effective. This review sheds doubt where many thought there was certainty. It also suggests that intermittent pneumatic compression deserves more attention, as does the use of compression stockings by those able to put them on themselves. The message is clear-the effective management of venous leg ulcers requires compression and rigorous research.

Jacqui Fernell, RGN, MA Professional Head of Service/Senior Lecturer Worcester Royal Infirmary NHS Trust Worcester, UK 